\title{
Utilization of Rehabilitation Services at a Public Health Facility in KwaZulu-Natal
}

\author{
Jeanine D. Kisten ${ }^{1}$, Boikhutso Tlou ${ }^{1} \&$ Thembelihle P. Dlungwane ${ }^{1}$ \\ ${ }^{1}$ College of Health Sciences, School of Nursing and Public Health, Discipline of Public Health Medicine, \\ University of KwaZulu-Natal, Howard College, Durban, South Africa \\ Correspondence: Thembelihle Dlungwane, University of KwaZulu-Natal, School of Nursing and Public Health, \\ Howard College, George Campbell Building $2^{\text {nd }}$ Floor, Durban 4001, South Africa. Tel: 27-31-260-4308. E-mail: \\ dlungwane@ukzn.ac.za
}

Received: November 23, 2021 Accepted: January 10, 2022 Online Published: March 1, 2022

doi:10.5539/gjhs.v14n4p19 URL: https://doi.org/10.5539/gjhs.v14n4p19

\begin{abstract}
Background: Rehabilitation services are recognized as part of an essential service within all levels of care across the health system. The aim of the study was to assess the utilization of rehabilitation services at a public health facility.

Method: A cross-sectional design was implemented. Data were collected utilizing a questionnaire. A systematic random sampling strategy was used. Descriptive statistics were summarised using frequencies and binary logistic regression model was used. A p-value less than 0.05 was deemed statistically significant.

Results: Eighty-three (26.3\%) participants utilized rehabilitation services. The most common reason for utilizing rehabilitation services at the public health facility was close proximity $23(28 \%)$ whilst $18(22 \%)$ of the participants highlighted that they had been referred to the hospital. Fifteen participants $(18 \%)$ reported that they utilized the chosen health facility due to personal preference and $12(14 \%)$ indicated that the facility was the only one they knew. Nine (11\%) participants utilized the facility due to reduced transport cost incurred and six (7\%) of participants chose a facility due to the perceived reduced waiting times in comparison to other facilities. Race was strongly associated with utilization of rehabilitation services.

Conclusion: The utilization of rehabilitation services in the public health facility was low. Convenience and patient referral to the hospital were the main reasons why patients chose a facility. The health professionals involved in rehabilitation services should raise awareness about the services available in the facility.
\end{abstract}

Keywords: Health services, healthcare utilization, rehabilitation services, public health facility

\section{Introduction}

The World Health Organization (WHO) recognizes rehabilitation as a needed health service to ensure the realization of universal health coverage. (World Health Organisation, 2018) Rehabilitation services are utilised by people across the lifespan to optimize their engagement with daily activities (Louw, Twizeyemariya, Grimmer\& Leibbrandt, 2019)._There is an increasing need for rehabilitation services at all levels of health care to ensure that patients are integrated well into their home environment (Caplan, 2011).

The WHO has estimated that one billion people require rehabilitation and the demand for rehabilitation services is greater in developing countries (WHO, 2019). Rehabilitation services include physiotherapy, occupational therapy, audiology and speech therapy (Kumar, 2012). The choice of selecting rehabilitation services is largely dependent on the availability of beds, geographical location of the health facility and transport (Caplan, 2011). Factors that influence a patient's decision to utilize healthcare services and rehabilitation are dependent on cultural and social influences (Luiz J, 2004). Poverty, quality of care, availability of resources, and service delivery contributes to the utilization of health care services (Sibiya, 2013; Adam, 2014; Chia, 2014). In addition, competent human resources are crucial in promoting utilization of health services (Adam, 2014).

Rehabilitation is not an optional health service for those who live in urban areas or those that can pay for private insurance (WHO, 2019). Rehabilitation services should not be viewed as an alternative when preventive and curative interventions fail. Rehabilitation services should be accessible and affordable to all patients irrespective of their social or economic background (WHO, 2019). Furthermore, rehabilitation interventions should commence in 
the early phase of in order to prevent secondary health conditions.

South Africa (SA) has reported a high burden of communicable diseases and non-communicable diseases respectively. The progression of communicable diseases may cause neurological impairments, dementia, mental illness, TB of the spine, joint disease, pain and fatigue (National Department of Health, 2016). Furthermore, these health conditions often impact on one's physical functioning and may develop impairments (National Department of Health, 2016; WHO, 2019). This means that more patients will need rehabilitation services to regain maximum function and increase their physical and environmental independence.

The demand for rehabilitation services is largely unmet due to a number of factors such as: inadequate rehabilitation services in rural settings, prolonged waiting times, shortage of assistive technologies and devices (WHO, 2019). Majority of patients in KZN seek rehabilitation care for injuries as a result of trauma, HIV-related disabilities, musculoskeletal and medical conditions. There is paucity of literature with regards to utilization of rehabilitation services in public health facilities in SA. The study purpose was to assess the utilization of rehabilitation services at a public health facility in KwaZulu-Natal (KZN).

\section{Methodology}

A cross-sectional survey was conducted. Patients who sought treatment at the facility's outpatient unit were recruited. In KZN, there are 61 hospitals and 178 clinics which are operated by the public health sector. The chosen facility is a regional hospital with a bed capacity of 543. The hospital is one of the major hospitals located in a suburb in the eThekwini health district. The facility offers a comprehensive package of care and has a catchment population of over 1500000 which makes this facility suitable to conduct the study. The facility offers both out-patient and in-patients which includes obstetrics and gynaecology, orthopedics, surgery, intensive care, pediatrics, and medical units. Rehabilitation services consists of physiotherapy, occupational therapy, audiology and speech and hearing therapy. The rehabilitation services are subsidized up to $40 \%$ of total costs and the charges are based on one's income. A systematic random sampling approach was used. The first participant was selected at random and thereafter every third person was selected to achieve the targeted the number. A standardised questionnaire was used. Variables measured in the questionnaire included demographic information, utilisation of rehabilitation services which includes which rehabilitation department they are coming to on that day, (iii) reasons for accessing rehabilitation services at that public health facility.

The data were coded and entered in a Microsoft Excel spreadsheet and then exported into SPSS version 27. Frequency distribution tables and graphs (bar and pie charts) were used to summarise the demographic characteristics and the distribution of the utilization of the rehabilitation services. Logistic regression was used to determine the socio-demographic characteristics associated to the utilization of rehabilitation services. The variables that were shown to be significant $(\mathrm{p}<0.05)$.

The researcher obtained approval from the University of KwaZulu-Natal (BE427/18), and the KwaZulu-Natal Department of Health (KZ_2018_) Each study participant received an information sheet and provided written informed consent.

\section{Results}

Of the 424 questionnaires administered, 376 were adequately completed yielding the response rate of $98 \%$. The average age of the participants was 55(SD 14.7) with majority being female ( $\mathrm{n}=247 ; 68.4 \%)$ and aged between aged between 31 and 55 years $(\mathrm{n}=202 ; 57.5 \%)$. Most of the participants were employed $(\mathrm{n}=218 ; 58 \%)$, utilized public transport $(\mathrm{n}=249 ; 76.4 \%)$ and earned between R0-R5 $000(\mathrm{n}=125 ; 65 \%)$ per month. Almost half of the participants $(n=176 ; 51.6 \%)$ resided more than $10 \mathrm{~km}$ from the regional hospital, were Indian $(n=198 ; 54 \%)$ and had less than a matric qualification $(\mathrm{n}=154 ; 45.6 \%)$. (Table 1$)$ 
Table 1. Sociodemographic profile of participants utilizing the facility $(n=376)$

\begin{tabular}{|c|c|c|}
\hline Demographic characteristics & Number & Percentage \\
\hline \multicolumn{3}{|l|}{ Age (years) } \\
\hline$(18-30)$ & 74 & 21.1 \\
\hline$(31-55)$ & 202 & 57.5 \\
\hline$(56-70)$ & 58 & 16.5 \\
\hline$(70+)$ & 17 & 4.8 \\
\hline Missing & 25 & \\
\hline \multicolumn{3}{|l|}{ Gender } \\
\hline Female & 247 & 68.4 \\
\hline Male & 114 & 31.6 \\
\hline Missing & 15 & \\
\hline \multicolumn{3}{|l|}{ Race group } \\
\hline Black & 153 & 41.7 \\
\hline White & 5 & 1.5 \\
\hline Indian & 198 & 54 \\
\hline Coloured & 4 & 1.4 \\
\hline Other & 4 & 1.4 \\
\hline Missing & 12 & \\
\hline \multicolumn{3}{|l|}{ Educational Status } \\
\hline Matric & 154 & 45.6 \\
\hline No matric & 145 & 42.9 \\
\hline Diploma & 24 & 7.1 \\
\hline Degree & 15 & 4.4 \\
\hline Missing & 38 & \\
\hline \multicolumn{3}{|l|}{ Employment status } \\
\hline Employed & 218 & 58 \\
\hline Unemployed & 127 & 33.8 \\
\hline Missing & 31 & \\
\hline \multicolumn{3}{|l|}{ Participants that reside: } \\
\hline within $10 \mathrm{~km}$ of the hospital & 165 & 48.4 \\
\hline more than $10 \mathrm{~km}$ from the hospital & 176 & 51.6 \\
\hline Missing & 35 & \\
\hline \multicolumn{3}{|l|}{ Mode of transport } \\
\hline Private & 80 & 21.3 \\
\hline Public & 257 & 68.4 \\
\hline Missing & 39 & \\
\hline \multicolumn{3}{|l|}{ Income levels (in ZAR) } \\
\hline$(0-5000)$ & 125 & 61 \\
\hline$(5001-10000)$ & 48 & 23.4 \\
\hline (10 001-14 000) & 4 & 2 \\
\hline (14 001 and above) & 28 & 13.7 \\
\hline Missing & 171 & \\
\hline
\end{tabular}

Figure 1 below shows the distribution of the utilization of rehabilitation services, approximately $74 \%$ of the participants were not utilizing rehabilitation services, whereas $26 \%$ were utilizing rehabilitation services. 


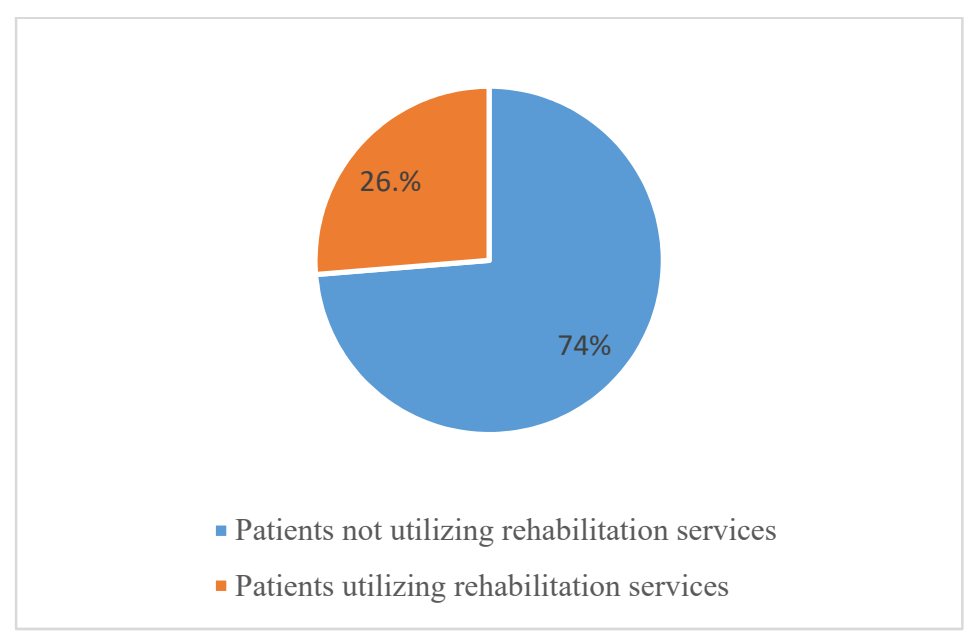

Figure 1. Distribution of Patients' utilization of rehabilitation services

Figure 2 below shows the various rehabilitation services used participants. Approximately, $49 \%$ of the participants were utilizing physiotherapy, $35 \%$ were using occupational therapy and $16 \%$ were utilizing speech and audiology services.

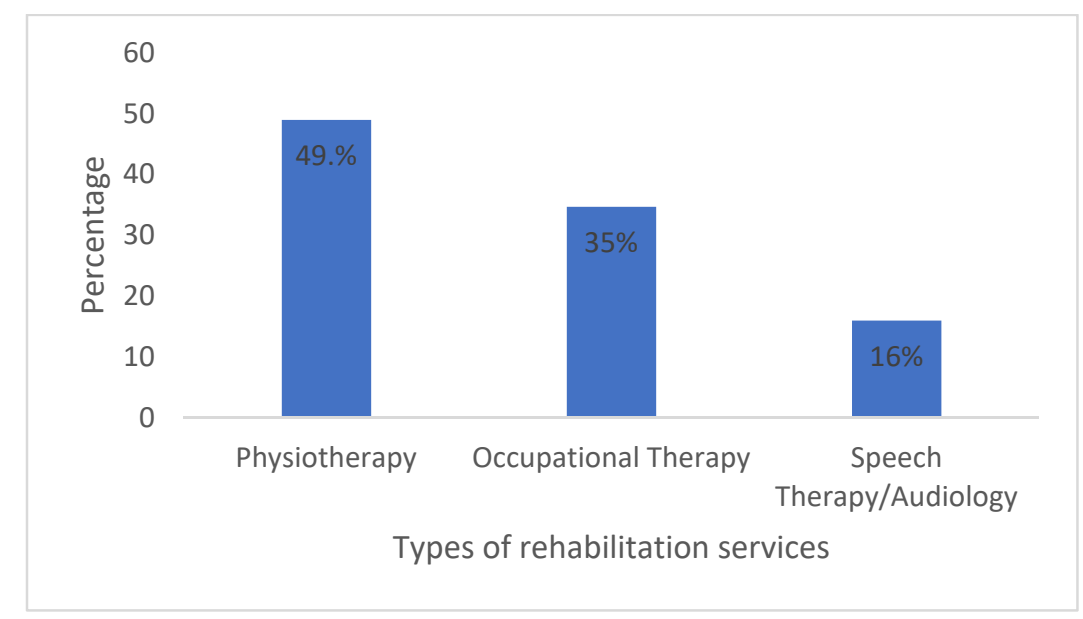

Figure 2. Types of rehabilitation services used by patients

Secondly the study sought to identify reasons that influenced the participants' decision to utilize rehabilitation services at the public health facility. Eighty-three (26.3\%) of the participants indicated that they were utilizing rehabilitation services. The most common reason for utilizing rehabilitation services at the public health facility was that the facility was closest to them $23(28 \%)$ whilst the main reason for $15(18 \%)$ of the participants was that they had been referred to the hospital by nearby facilities. Sixteen participants $(19 \%)$ reported that it was their personal preference to utilize the chosen health facility and $14(17 \%)$ indicated that the facility was the only one they knew. Nine (11\%) participants utilized the facility due to reduced transport cost incurred and six (7\%) of participants chose the facility based on perceived reduced waiting times (Table 2).

Table 2. Reasons for utilizing rehabilitation services at the public health facility $(n=83)$

\begin{tabular}{lll}
\hline Reasons for using public facility for rehabilitation services & Frequency & Percentage \\
\hline Only facility I know & 14 & 17 \\
Nearest facility to me & 23 & 28 \\
Reduced waiting time & 6 & 7 \\
Referred to the facility & 15 & 18 \\
Personal preference & 16 & 19 \\
Transport cost is cheaper & 9 & 11 \\
\hline
\end{tabular}


Thirdly, the relationship between participants' utilization of rehabilitation services and sociodemographic characteristics was established. Race was significantly associated to the utilization of rehabilitation services. Black participants were approximately 4 times $(\mathrm{aOR}=4.22$ [95\% CI: $1.42,12.6])$ more likely to utilize rehab services when compared to other racial groups accessing the hospital. More still, participants earning between R5 $001-$ R10 000 were 3 times ( $\mathrm{aOR}=2.97$ [95\% CI: $0.52,17.06])$ more likely to utilize rehabilitation services compared to those earning more than R14000. Furthermore, participants who had matric or a higher education qualification were more likely $(\mathrm{aOR}=1.88$ [95\% CI: $0.72,4.87])$ to use rehabilitation services when compared to those with an education qualification less than matric. Unemployed participants were also more likely (aOR $=1.14$ [95\% CI: $0.67,1.96])$ to utilize rehabilitation services when compared to the employed ones. Table 3 summarises the logistic regression for the factors associated to the utilization of rehabilitation services.

Table 3. Relationship between participants utilization of rehabilitation services and sociodemographic characteristics $(\mathrm{n}=376)$

\begin{tabular}{|c|c|c|c|}
\hline Characteristics & Odds ratio & CI & Pp - value \\
\hline \multicolumn{4}{|l|}{ Gender } \\
\hline Female & 0.91 & $0.65-2.25$ & 0.83 \\
\hline \multicolumn{4}{|l|}{ Male (ref.) } \\
\hline \multicolumn{4}{|l|}{ Age } \\
\hline$(18-30)$ & 0.51 & $0.03-10.60$ & 0.67 \\
\hline$(31-55)$ & 0.46 & $0.03-8.42$ & 0.60 \\
\hline$(56-70)$ & 0.24 & $0.02-6.11$ & 0.39 \\
\hline \multicolumn{4}{|l|}{$70+($ ref. $)$} \\
\hline \multicolumn{4}{|l|}{ Race } \\
\hline Black & 4.22 & $1.42-12.60$ & $0.01 *$ \\
\hline \multicolumn{4}{|l|}{ Other races (ref.) } \\
\hline \multicolumn{4}{|l|}{ Distance } \\
\hline Less than $10 \mathrm{~km}$ & 2.05 & $0.79-5.33$ & 0.14 \\
\hline \multicolumn{4}{|c|}{ greater than $10 \mathrm{~km}$ (ref.) } \\
\hline \multicolumn{4}{|l|}{ Income status } \\
\hline R0 - R5 000 & 1.83 & $0.34-9.82$ & 0.48 \\
\hline R5 $001-$ R10 000 & 2.97 & $0.52-17.06$ & 0.22 \\
\hline \multicolumn{4}{|c|}{ more than R 14001 (ref.) } \\
\hline \multicolumn{4}{|l|}{ Mode of transport } \\
\hline Public & 0.99 & $0.34-2.93$ & 0.99 \\
\hline \multicolumn{4}{|l|}{ Level of education } \\
\hline Matric or more & 1.88 & $0.72-4.87$ & 0.19 \\
\hline \multicolumn{4}{|l|}{ No Matric (ref.) } \\
\hline \multicolumn{4}{|c|}{ Employment status } \\
\hline Unemployed & 1.14 & $0.67-1.96$ & 0.62 \\
\hline Employed (ref.) & & & \\
\hline
\end{tabular}

\section{Discussion}

The purpose of this study was to assess the utilization of rehabilitation services at a public health facility in KZN. The current study findings indicated that $26.3 \%$ of patients utilized rehabilitation services at the health facility. The 
low utilization of rehabilitation services is a great concern considering that KZN has a high burden of non-communicable diseases, injury, TB and HIV which has an impact on the need for rehabilitation services (KZN, 2015). Previous studies reported low utilization and accessibility of rehabilitation services (Leitarts, 2014; Alshehri, 2018). The low utilization of rehabilitation services could be attributed to a lack or awareness of rehabilitation coupled with poor referral systems and to prejudices associated with rehabilitation services (Leitarts, 2014; Adam, 2014).

Most of the patients in this study reported that there were utilising physiotherapy services. Rehabilitation professionals include occupational therapists, physiotherapists, speech therapists and audiologists. Each type of rehabilitation therapy can be accessed in various healthcare settings such as inpatient, outpatient and community-based rehabilitation services. The key focus is to restore and improve function and mobility. Rehabilitation services are essential in preventing disease progression and complications. This in turn improve the quality of life and as well as improved reduce disabling effects that result from chronic illnesses and injuries. The inclusion of rehabilitation services within the health care system offer a continuum of a multidisciplinary and coordinated approach. Socio-economic factors have large influence on the utilization of health care services (Stellenberg, 2015). Social, cultural and environmental circumstances reflect choices to utilize healthcare (Chia, 2014). The current study found that geographical location and referral patterns were reported as the common reasons for using rehabilitation services at the public health facility. This concurs with the findings of a study done in Kenya which concluded that distance influences utilization of medical and health services (Prosser, 2007).

Patient's perceptions and attitudes plays a major role in the utilization of health services (Buor, 2005). The individual preferences are largely associated with perceived need, past experiences and health literacy. In addition, patient's preferences are influenced by quality of health services, staff attitudes and availability of equipment (Adam, 2014). About a third of the participants reported that they preferred to utilized the chosen health facility. Further study needs to be conducted to establish what influenced the patient's preferences to utilise rehabilitation services at the public health facility.

The financial cost incurred to travel to a health institution can pose a barrier to utilization of health services. Perceived high costs of services could lead to low utilization of health services (Grut, 2012). Some participants in this study highlighted that the utilized the rehabilitation services at the facility because they do not spend a lot on transport for travelling.

Waiting time is an essential predictor of health service utilisation, and patient's satisfaction. Waiting times in public health facilities impacts on the patient's perception of health services and indirectly influence the decision to utilise health services at that health facility (Ogaji, 2017). To achieve a positive patient experience, in an out-patient setting, research has shown that waiting time is a crucial health service factor (Ogaji, 2017). The participants of this study indicated that they chose the facility based on the perceived reduced waiting times when compared to other facilities.

Access to health services is often associated with race (Nattrass, 2001). Health disparities have been extensively documented in SA as a result of racial divisions brought about by the legacy of apartheid (Knight, 2009; Coovadia, 2009). Black patients in South Africa, make up $52 \%$ of the total number of patients who utilize public health facilities (McLaren, 2014). This study found that black patients were most likely to utilize rehabilitation services more than any other race group at the hospital.

\subsection{Study Limitations}

The study was conducted in a public health facility in one health district. Further study needs to be conducted to establish the utilisation of rehabilitation services in other districts within KZN province. Furthermore, this study was an exploratory descriptive study and did not seek the level of quality of care and what rehabilitation services does for these patients. A qualitative study should be conducted to explore this further.

\section{Conclusion}

The utilization of rehabilitation services in the public health was low. Participants utilised rehabilitation services based on their perceived waiting times, personal preference, patient referral and geographical location to the health facility. The health professionals involved in rehabilitation should raise awareness about the availability of rehabilitation services in public health facilities.

\section{Acknowledgements}

The authors acknowledge the participants of the study. 


\section{Authors' Contributions}

JK- Principal author was responsible for the development of the conceptualisation, analysis and writing of the manuscript as part of the Master's degree.

T.D- was responsible for supervising the entire thesis and helped in the writing of the manuscript.

BT- was responsible for data analysis.

\section{Competing Interests Statement}

The authors declare that there are no competing or potential conflicts of interest.

\section{References}

Adam, V. Y., \& Awunor, N. S. (2014). Perceptions and factors affecting utilization of health services in a rural community in Southern Nigeria. Journal of Medicine and Biomedical Research, 13(2), 117-24. Retrieved from https://www.researchgate.net/publication 28137432

Alshehri, M. A., Alhasan, H., Alayat, M., Al-subahi M., Yaseen, K., \& Ismail, K. (2018). Factors affecting the extent of utilization of physiotherapy services by physicians in Saudi Arabia. Journal of Physical Therapy Science, 30(2), 216-22. https://doi.org/10.1589/jpts.30.216

Buor, D. (2005). Determinants of utilisation of health services by women in rural and urban areas in Ghana. GeoJournal, 61(1), 89-102. https://doi.org/10.1007/s10708-005-1929-6

Caplan, G. A. (2011). Rehabilitation. Journal of the American Medical Directors Association, 12(1), 8. https://doi.org/10.1016/j.jamda.2010.03.008

Chia, E. H. S., Tee, W., \& Tse Lin Ho, E. (2014). Expectations and perceptions of patients on the transfer of care to the primary healthcare setting. International Journal of Integrated Care, 14(9). https://doi.org/10.5334/ijic.1866

Coovadia, H., Jewkes, R., Barron, P., Sandars, D., \& Mcintrye, D. (2009). The health and health system of South Africa: historical roots of current public health challenges. Lancet, 374(9692), 817-34. https://doi.org/10.1016/S0140-6736(09)60951-X

Grut, L., Mgi, G., Braathen, S. G., \& Ingstad, B. (2012). Accessing community health services: challenges faced by poor people with disabilities in a rural community in South Africa. African Journal of Disability, 1(1), 1-7. https://doi.org/10.4102/ajod.v1i1.19

Knight, L., \& Maharaj, P. (2009). Use of public and private health services in KwaZulu-Natal, South Africa. Development Southern Africa, 26(1), 17-28. https://doi.org/10.1080/03768350802640040

Kumar, S., Gautam, R., \& Sitanshu Sekhar, K. (2012). Disability and rehabilitation services in India: Issues and challenges. Journal of Family Medicine and Primary care [Internet], 1(1), 69-73. https://doi.org/10.4103/2249-4863.94458

KZN, Health Department Strategic Plan. (2015). Strategic plan 2015-2019. Retrieved 2016, from http://www.kznhealth.gov.za/Strategic-Plan-2015-2019.

Leibbrandt, D., Louw, Q., Twizeyemariya., \& Grimmer, K.(2019). Estimating the costs and benefits of stroke rehabilitation in South Africa. Journal of evaluation in clinical practice. https://doi.org/10.1111/jep.13287

Leitarts, I. (2014). The study "rehabilitation services". shs web of conferences, 10(00020). https://doi.org/10.1051/shsconf/20141000020

Luiz, J., \& Wessels, M. (2004). Changes in the provision of health care in South Africa. South African Journal of Business Management, 35(3), 1-12. https://doi.org/10.4102/sajbm.v35i3.657

McLaren, Z. M., Ardington, C., \& Leibbrandt, M. (2014). Distance decay and persistent health care disparities in South Africa. BMC Health Services Research, 14(1), 541-55. https://doi.org/10.1186/s12913-014-0541-1

National Department of Health. (2016). Policy framework and strategy for disability and rehabilitation services in South Africa. Retrieved from https://doi.org/10.5539/gjhs.v12n4p1

Nattrass, N., \& Seeking, J. (2001). "Two Nations"? Race and Economic Inequality in South Africa Today. Daedalus, 130(1), 45-70. Retrieved from https://www.jstor.org/stable/20027679

Ogaji, D. S. (2017). Waiting time and patient satisfaction: Survey of patients seeking care at the general outpatient clinic of the University of Port Harcourt Teaching Hospital. Medical Journal, 11, 148-55. 
https://doi.org/10.4103/phmj.phmj_41_17

Prosser, T. (2007). Utilization of health and medical services: factors influencing health care seeking behaviour and unmet health needs in rural areas of Kenya. https://ro.ecu.edu.au/theses/46

Sibiya, M. N., \& Gwele, N. S. (2013). A model for the integration of primary health-care services in the province of KwaZulu-Natal. Journal of Nursing Management, 21(2), 387-95. https://doi.org/10.1111/j.1365-2834.2012.01420.x

Stellenberg, E. L. (2015). Accessibility, affordability and use of health services in an urban area in South Africa. Curationis, 38(1), 1-7. https://doi.org/10.4102/curationis.v38i1.102

World Health Organisation [WHO]. (2018). Monitoring health for the SDGs, sustainable development goals. Retrieved from http://www.whoint/gho/publications/world_health_statistics/2017/en/

World Health Organisation [WHO]. (2019). World report on disability. Retrived from https://www.who.int/rehabilitation/rehabilitationguide-for-action/en/

\section{Copyrights}

Copyright for this article is retained by the author(s), with first publication rights granted to the journal.

This is an open-access article distributed under the terms and conditions of the Creative Commons Attribution license (http://creativecommons.org/licenses/by/4.0/). 